\title{
Peste en una ciudad novohispana. El matlazahuatl de 1737 en la Puebla de los Ángeles
}

\author{
Miguel Ángel Cuenya \\ Instituto de Ciencias Sociales y Humanidades \\ Universidad Autónoma de Puebla (México)
}

En 1737-1738 la Nueva España se vio sacudida por la peste. Mortífera enfermedad denominada con el nombre de "matlazahuatl", que atacaba sin distinción de edad, sexo, grupo étnico o económico, ocasionando estragos difíciles de olvidar y consecuencias económicas, demográficas y sociales que perduraban durante largo tiempo. En Puebla, como en todo centro urbano colonial, sus habitantes estaban acostumbrados a convivir diariamente con la muerte, y desde la fundación de la ciudad diversas pandemias y epidemias habían afectado a su población. A pesar de ello, los poblanos no recordaban una enfermedad tan letal como el matlazahuatl, que ocasionara un número tan elevado de víctimas, ya que en sólo ocho meses se registró el entierro de 7.167 personas adultas (15\% de su población). A diferencia de la viruela, el sarampión y otras enfermedades, la peste superó barreras étnicas y socioeconómicas: indígenas y castas fueron los grupos que sintieron con mayor intensidad los efectos de la terrible enfermedad y el golpe fue tan severo que las consecuencias se sintieron durante muchos años, mientras que mestizos y españoles se recuperaron rápidamente.

Sobre las crisis de mortalidad que afectaron a las sociedades del pasado, y que contamos con el mayor número de descripciones, fueron aquellas que causaron verdaderas catástrofes demográficas, como la peste europea de los siglos XIV-XV y el colapso de la población indígena americana en el siglo XVI. Estas afectaron profundamente la estructura demográfica, así como la actividad económica, social y cultural de pueblos, ciudades, regiones y reinos, estableciendo verdaderos cortes en la historia de esas sociedades.

Desde el siglo XVI tres tipos de patologías coexistieron simultáneamente en territorio mesoamericano generando, a partir de ese momento, mortíferas pandemias, epidemias y endemias a lo largo de todo el período colonial y gran parte del siglo XIX. En primer lugar encontramos la llamada patología biológica, de la que forman parte la viruela, el sarampión, paperas, tosferina y varicela, enfermedades que para reproducirse requerían del contagio directo de hombre a hombre. Paralelamente, otro tipo de patología, la social, iba creando condiciones propicias para el desarrollo de los 
agentes patógenos; hambre, guerra, alcoholismo, desgano vital, desnutrición, tifo, tifoidea, fiebre amarilla y disentería, se fueron generando al interior de los pueblos indígenas. Finalmente, encontramos que conjuntamente a las patologías biológica y social, surgió desde el siglo XVI la patología biosocial, caracterizada fundamentalmente por la peste, conocida también como matlazahuatl o cocoliztle; enfermedad que sin importar el carácter de las poblaciones, atacaba sin distinción de edad, sexo o nivel socio-económico. Sólo se necesitaban ciertas condiciones sociales - hacinamiento, promiscuidad y falta de higiene- para que se facilitara el contagio. ${ }^{1}$

En todos los casos, el indígena fue proporcionalmente el grupo más afectado. Sus condiciones de vida, actividad laboral, alimentación, hacinamiento y salubridad hicieron de este sector el de mayores posibilidades de contagio, mientras que los españoles mostraban el lado opuesto: buena alimentación, vivienda, disponibilidad de agua dulce e ingresos económicos más elevados, permitiéndoles sortear con mayores probabilidades de éxito los períodos de sobremortalidad.

\section{El matlazahuatl}

La mayoría de las crónicas relatan y describen los efectos de terribles cocoliztlis - cuyo significado era enfermedad o pestilencia- que cegaron la vida de millones de indígenas. Uno de los más mortíferos entre las patologías coloniales, fue el matlazahuatl.

El término matlazahuatl, vocablo nahuatl, expresaba los signos externos más visibles de la enfermedad. Nicolás León señala que significa "matlatl, red; zahuatl, sarna, erupción, granos, etc. Erupción como red o en forma de red (matla-zahuatl)".2

1 Malvido, Elsa: "Las epidemias: una nueva patología”, en Moreno de los Arcos, Roberto y Aguirre Beltrán, Gonzalo (Coord.): Historia general de la medicina en México, México, 1991.

2 León, Nicolás: “¿Qué era el matlazahuatl y qué el cocoliztli en los tiempos precolombinos y en la época hispana?”, en: Florescano, Enrique y Malvido, Elsa (Coord.): Ensayos sobre historia de las epidemias en México, México, 1982, Tomo I, págs. 383-384. Por su parte, el presbítero Cayetano Cabrera Quintero, quien realizó un pormenorizado estudio de la pandemia de matlazahuatl de 17361738, nos comenta que el pueblo la llamó "en el idioma del país: matlazahuatl, voz compuesta de matlatl, la red, y por lo parecido, el redaño, y de zahuatl, la pústula o granos, con que sin ver lo que decían la venían a llamar granos en el redaño, o red de granos". Cabrera y Quintero, Cayetano: Escudo de Armas de México. Escrito por el presbítero para conmemorar el final de la funesta epidemia de matlazahuatl que asoló a la Nueva España entre 1736 y 1738, México (1746),1981, edición facsimilar, págs. 59-60. 
Alrededor del carácter de esta enfermedad se generó una larga discusión académica que perdura hasta nuestros días. El origen de la polémica parte de la confusión existente sobre los términos peste y cocoliztli que son generales a enfermedad. ${ }^{3}$ Sobre el punto en que todos los investigadores coinciden es en que el matlazahuatl ocasionó verdaderas catástrofes demográficas, entre las que se encuentran las pandemias de 1545-1548, 1576-1579, 1615-1616, 1641-1643, 1696, 1736-1738 y 1772-1773, pero no sucede lo mismo al intentar caracterizarla.

La enfermedad, que en el siglo XVI fue conocida genéricamente como cocoliztli, tuvo tantos nombres como síntomas externos presentó; se denominó también matlazahuatl, vocablo que terminó por designar el mal durante los siglos XVII y XVIII. La gravedad de la dolencia y los estragos que ocasionó a la población novohispana, llevó a diversos médicos a estudiarla con la finalidad de establecer la terapéutica que consideraban indispensable para salvar de una muerte segura al enfermo. ${ }^{4}$

Todos los autores remarcan las características más sobresalientes: fiebre muy elevada, flujo de sangre por nariz, boca y oídos, intenso dolor de estómago y disentería. No nos cabe la menor duda de "que se trató de una enfermedad grave, con sintomatología bastante precisa y que afectaba a

3 Con el término genérico de cocoliztli se hacía referencia a diversas enfermedades o pestilencias. Estas fueron "observadas, estudiadas y clasificadas por los médicos indígenas, quienes captaron y destacaron las peculiaridades de cada una de ellas, empleando la estructura polisintética de la lengua nahuatl, para expresarlas. Llamaron hueyzahuatl a la viruela, tepitonzahuatl al sarampión, quechopotzahualiztli a las paperas, tlatlaciztli o tos chichimeca a la tos ferina", etc., Malvido, Elsa y Viesca, Carlos: "La epidemia de cocoliztli de 1576", en Historias, México, año I, n. o 11, pág. 27.

4 Durante la gran pandemia de 1576, el médico español Francisco Hernández, protomédico de las Indias, publicó un tratado titulado "De la enfermedad de la Nueva España en el año de 1576, llamada por los indios cocoliztli", en donde realiza una interesante e ilustrativa descripción de la misma: “...las fiebres eran contagiosas, abrasadoras y contínuas, más todas pestilentes y, en gran parte letales. La lengua seca y negra. Sed intensa, orinas de color verde marino, verde (vegetal) y negro, más de cuando en cuando pasando de la coloración verdosa a la pálida. Pulsos frecuentes y rapidos, más pequeños y débiles; de vez en cuando hasta nulos. Los ojos y todo el cuerpo amarillos. Seguía delirio y convulsión, postemas detrás de una o ambas orejas, y tumor duro y doloroso, dolor de corazón, pecho y vientre, temblor y gran angustia y disenterías; la sangre que salía al cortar una vena, era de color verde o muy pálido, seca y sin ninguna serocidad. Algunas gangrenas y escéfalos invadían los labios, las partes pudendas y otras regiones del cuerpo con miembros putrefactos, y les manaba sangre de los oídos; a muchos en verdad fluíales la sangre de la nariz, de los que recaían casi ninguno se salvaba. Con el flujo de la sangre de la nariz muchos se salvaban, los demás perecían. Los atacados de disentería en su mayor parte ordinariamente se salvaban, ni los abscesos detrás de la oreja eran mortales, si en modo alguno retrocediesen, sino que espontáneamente maduraban, o daba la salida con los cauterios por lo agujeros, aun en los abscesos inmaduros fluyere la parte líquida de la sangre, o se eliminara el pus, tras de lo cual quedaría también eliminada la causa de la enfermedad". Citado por Somolinos D'Ardois, Germán: "La epidemia de cocoliztli de 1545 señalada en un códice", en: Florescano, Enrique y Malvido, Elsa (Coord.): Ensayos sobre historia de las epidemias..., Tomo I, págs. 374-375. 
todo el organismo, la cual presentaba a veces formas abortivas caracterizadas por localizarse principalmente en forma de bubones retroarticulares e inguinales". ${ }^{5}$

Ahora bien, ¿de qué enfermedad se trataba?. Esta ha sido la gran dificultad a la que se han enfrentado historiadores y médicos al tratar de identificar y precisar la dolencia partiendo de las descripciones existentes del cuadro clínico, con las variantes que presentó a lo largo de casi cuatro siglos. El problema central radica en que muchas afecciones son difíciles de identificar en la medida que éstas deben ubicarse en un contexto histórico-biológico en permanente cambio a través del tiempo. La peste - como otros padecimientos - puede presentar variaciones debido a la mutación del propio agente, y a la capacidad evolutiva del complejo patógeno en que se inscribe.

Debemos tener presente también, que la Pasteurella Pestis podía presentarse en diversas formas (bubónica, septicémica o hemorrágica) y, que la población aborigen americana — sin ningún tipo de defensa inmunológica ante un bacilo totalmente desconocido- podría haber reaccionado de manera atípica. En este sentido, consideramos que los médicos españoles del siglo XVI, que conocían perfectamente a la peste y sus diferentes manifestaciones, si bien se encontraron con una manifestación diferente a la europea, no necesitaron realizar una referencia explícita sobre su identidad, de ahí que utilizaran de manera indistinta los términos españoles "peste" y "pestilencia", o los indígenas cocoliztli y matlazahuatl. El presbítero Cayetano Cabrera y Quintero, que escribe a finales de la década de 1730, no realiza en ningún momento diferenciación alguna, es más, establece una correlación entre las pandemias de peste que asolaron el mundo antiguo y el cocoliztli o matlazahuatl de 1576 y $1737 .{ }^{6}$ A lo largo de toda la obra, emplea como sinónimos las palabras peste, pestilencia, cocoliztli y matla-

5 Malvido, Elsa y Viesca, Carlos: "La epidemia de cocoliztli...”, pág. 85.

6 "Con médica no menos que poética energía introdujo a Apolo el grande Homero hiriendo de peste los exércitos de los griegos...Y assi halló este enemigo en las tablas de las historias. En la horrible peste, que por el año de quinientos noventa y quatro al veinte y ocho el emperador Justiniano, prendiendo por el oeste abrasó casi todo el orbe, llevándose la tercera parte de los hombres; y de que solo en Constantinopla morían cinco mil cada dia...Pero en la que mostró Dios más claro que peleaba fue en la que por el año de 590 corrió a la par del Tiber en Roma; llevóse entre millares de vecinos al SS. Papa Pelagio...No fue tanta la barbaridad de nuestros antiguos mexicanos, que no les dejase algún acumen para penetrar esta verdad. Aquella dolencia que en la era presente y la antigua, los ha contagiado tantas veces, llamaron con nativa elegancia cocoliztli...[declarando Dios] la mayor pestilencia que han padecido después de la conquista estos Reynos: en la que se lloró por el año de 1576". Cabrera y Quintero, Cayetano: Escudo de armas..., págs. 3-4. 
zahuatl, otorgándole — por lo tanto — al vocablo matlazahuatl la acepción europea de peste que se tenía en la época. ${ }^{7}$ En este sentido, los distintos nombres dados a la enfermedad desde el siglo XVI al XVIII, podrían hacer referencia a las distintas manifestaciones de la misma o, también, a la sintomatología predominante.

\section{La difusión del matlazahuatl: la pandemia en la Nueva España}

La enfermedad — de acuerdo a lo señalado por diversos autores - 8 comenzó a manifestarse a finales del mes de agosto de 1736 en el pueblo de Tacuba, distante apenas una legua de la capital virreinal. Los primeros síntomas se observaron entre los sirvientes de un obraje lanero, ${ }^{9}$ quienes comenzaron a ser atacados por una fiebre extraña y mortal. Inmediatamente se responsabilizó al consumo - por parte de los operarios del taller - "de un barril de aguardiente contrahecho". ${ }^{10}$ La Iglesia — por su parte— asoció los inusuales acontecimientos del año 1736 (temblores de tierra, lluvias copiosas y eclipses de sol) y la extraña enfermedad a un castigo celestial. ${ }^{11}$

7 Peste: "enfermedad contagiosa, ordinariamente mortal, y que causa muchos estragos en la vida de los hombres y de los brutos. Ocasiónase por lo común de la infección del aire, y suelen ser la señal de ella unos bultos que llaman bubones u landres. Es del latino pestis...Las pestes y calamidades públicas son efecto de la ira de Dios". Pestilencia: "Lo mismo que peste". Diccionario de la lengua castellana, Madrid, 1737, III, pág. 5.

8 Cabrera y Quintero, Cayetano: Escudo de armas..., pág. 32; Orozco y Berra, Manuel: "Matlazahuatl de 1736", en: Diccionario Universal de Historia y Geografía, México, Tipografía de Rafael, 1853-1856, Tomo IX, Apéndice II, pág. 793; Cavo, Andrés: Historia de México, México, 1949.

9 El hecho de que el brote se manifestara en un obraje, nos remite necesariamente al problema de la lana. Un obraje, al contar con grandes depósitos, presenta condiciones ideales para la proliferación de piojos y roedores, empero, desconocemos el origen de ésta, por lo que debemos tomar — con las precauciones que el caso requiere - la información que sobre el particular anotan Cabrera y Quitero, Cayetano: Escudo de armas... y Orozco y Berra, Manuel: "Matlazahuatl de 1736". En la Puebla de los Ángeles, se registran las primeras defunciones debidas al matlazahuatl en la parroquia de San José, que concentraba en su jurisdicción un alto número de hilanderos y tejedores, lo cual no resulta casual.

10 Orozco y Berra, Manuel: "Matlazahuatl de 1736”, pág. 3.

11 El cristianismo desde sus orígenes estableció, siguiendo la tradición de los pueblos de la antigüedad, una estrecha relación entre enfermedad y pecado; en este sentido, "la visión de una enfermedad determinada como especial castigo de un gran pecado o de una vida pecaminosa fue harto frecuente en el mundo antigüo cristiano y durante la Edad Media europea". Santo Tomás, tomando a San Pablo, desarrolla la teoría del mysterium doloris; desde esta perspectiva, "la razón por la cual existen enfermedades y dolores en el tránsito terreno del hombre es, en último extremo, un misterio impenetrable. Dios causa las enfermedades o las permite, y el hombre trata de evitarlas o las combate con los recursos de su ingenio". Entralgo, Luis: Enfermedad y pecado, Barcelona, 1961, págs. 78 y 80. Ambas concepciones prevalecen en la sociedad novohispana del siglo XVIII. 
Frente a estas opiniones, azorados y desorientados, los médicos recordaron, tal como lo prescribía Hipócrates, las seis causas que habrían provocado la enfermedad: el aire, la comida y la bebida, el movimiento y la quietud, lo que se expulsa o se detiene, el sueño y el desvelo, y las pasiones del ánimo. ${ }^{12}$

Mientras los doctos galenos de la ciudad de México discurrían sobre su carácter, el matlazahuatl comenzó a expandirse hacia los pueblos cercanos. La rapidez del contagio fue tal que - anota el presbítero Cayetano Cabrera Quintero- la atención espiritual a los moribundos se convirtió en una pesada tarea, debido a que

"aun los enfermos se llegaron a ver tan confundidos, que al ministrarles la última, y
que allí era la primera medicina del Santo Óleo, se equivocaban pies ya ungidos, con
los que aun no estaban oleados; porque abrigada toda una familia bajo una manta que
avía servido al padre de capa, parecía un solo enfermo con cien pies". ${ }^{13}$

Con la intención de remarcar la gravedad de la situación, el cronista nos comenta que familias enteras sucumbieron; los sacerdotes encontraron muchas veces un espectáculo macabro:

"Caía muerto el marido, moribunda sobre él su consorte y ambos cadáveres eran el lecho en que yacían enfermos los hijos. Muchos halló la lástima asidos a los pechos de su difunta madre, chupando veneno en vez de leche". ${ }^{14}$

Cuando en octubre de 1736 llegó el matlazahuatl a la ciudad de México, el contagio se aceleró y todo el centro urbano se encontró envuelto bajo "un manto de muerte". El grupo más afectado fue el indígena y muchos barrios de la perdieron gran parte de sus habitantes.

Desde Tacuba la peste se expandió con rapidez asombrosa por todo el valle de México. ${ }^{15} \mathrm{El}$ avance de la terrible enfermedad siguió - fiel a la tradición - los caminos reales. Así, en enero de 1737 Atizapán, San Pedro Calimaya, Metepec, Tlayacapa y el valle de Toluca se encontraban bajo sus efectos. ${ }^{16}$ Para febrero había alcanzado Cuernavaca y, en marzo, Guanajuato en el norte, el Bajío en la zona central y Cholula, Acatzingo,

12 Cabrera y Quintero, Cayetano: Escudo de armas..., pág. 66.

13 Ibídem., pág. 50.

14 Ibídem., pág. 48.

15 Archivo General de la Nación, Secretaría del virreinato, Tributos, vol. 47, exp. 14; Cabrera y Quintero, Cayetano: Escudo de armas..., pág. 412.

16 Ibídem, fol. 383r; e Ibídem, págs. 224-225. 
Zacatelco, Tlaxcala, Tepeaca, Tepejí y la ciudad de Puebla en el oriente, luchaban denodadamente contra el "ángel de la muerte". ${ }^{17}$

\section{La ciudad de Puebla}

La Puebla de los Ángeles desde sus mismos orígenes (1531) adquirió gran importancia económica, cultural y religiosa, llegando rápidamente a convertirse en la segunda ciudad del virreinato. El nuevo centro urbano fue producto de un experimento social que le otorgó un rasgo peculiar, único en la Nueva España: villa de españoles no encomenderos, ${ }^{18}$ proyectada desde su misma fundación como ciudad, intentando nuclear en su seno a todos aquellos españoles pobres que quisieran trabajar la tierra tal como lo hacían en España.

Durante los siglos XVI y XVII, Puebla de los Ángeles fue una ciudad privilegiada en el contexto novohispano por su situación geográfica, por la existencia de abundante mano de obra indígena disponible, por el desarrollo de una industria importante, por su pujante actividad mercantil que hizo de ella el gran centro distribuidor de la colonia, y por haber mantenido el control sobre el principal valle cerealero del altiplano central (Atlixco). ${ }^{19}$ Esta situación la convirtió en un núcleo urbano ideal para el asentamiento de órdenes religiosas y la construcción de templos, que la erigieron como

17 Ibídem, págs. 113, 224, 225 y 412; Orozco y Berra, Manuel: "Matlazahuatl de 1736", pág. 794; López Mora, Rebeca: El gran matlazahuatl de 1737 en Nueva España, México, 1990, págs. 52 y ss; Alegre, Francisco Javier: Historia de la Provincia de la Compañía de Jesús en Nueva España, Roma, 1956-1960, III, pág. 418 y ss; Garavaglia, Juan Carlos y Grosso, Juan Carlos: "El comportamiento demográfico de una parroquia poblana de la colonia al México independiente: Tepeaca y su entorno agrario, 1740-1850", Historia Mexicana, t. 40, n. ${ }^{\circ}$ 4. 1991; Brinckman, Lutz: "Natalidad y mortalidad en Tecali (Puebla): 1701-1801", Siglo XIX, t. IV, n. ${ }^{\circ}$ 7. 1989; Calvo, Thomas: Acatzingo, demografía de una parroquia mexicana, México, 1973; Morin, Claude: Santa Inés Zacatelco (16461812). Contribución a la demografía histórica del México colonial, México, 1973, Cuenya, Miguel Ángel: Epidemias y mortalidad en la Puebla de los Ángeles en el período colonial, Puebla, 1989; Gibson, Charles: Los Aztecas bajo el dominio español, México, 1967.

18 La fundación de Puebla fue parte de un experimento destinado a proteger a los pueblos indígenas de la rapacidad y explotación de los conquistadores, al mismo tiempo que intentaba convencer a éstos de que podían sobrevivir labrando la tierra como lo hacían en España. Chevalier, François: Significación social de la fundación de la Puebla de los Ángeles, Puebla,1960; y Hirschberg, Julia: La fundación de Puebla de los Ángeles. Mito y realidad, Puebla, 1981.

19 Chevalier, François: Significación social de la fundación...; Fernández de Echeverría y Veytia, Mariano: Historia de la fundación de la ciudad de la Puebla de los Ángeles, Puebla (1780), edición facsimilar, 1990; Zerón Zapata, Miguel: La Puebla de los Ángeles en el siglo XVII. Crónica de la Puebla, México, 1945; Lierh, Reinhard: Ayuntamiento y oligarquía en Puebla, 1787-1810, México, 1971, 2 vols.; Thomson, Guy P.C.: Puebla de los Ángeles. Industry and Society in a Mexican City, 1700-1850, Syracuse, 1989 
el más importante centro religioso de la Nueva España, así como también, en un notable espacio cultural. ${ }^{20}$

Empero, al comenzar el siglo XVIII había dejado de ser el vigoroso polo económico, cultural y religioso alrededor del cual se había organizado un amplio territorio. La región había entrado en un marasmo económico que ocasionó su estancamiento y Puebla resintió este retraso. La decadencia urbana fue notoria: el comercio cerealero encontró competencia en la producción del Bajío y de otras áreas, que le hicieron perder mercados; la poderosa industria harinera, que empleaba a un importante número de trabajadores, entró en crisis; la competencia desplazó también al jabón, las ceras y el vidrio; el comercio con el Perú afectó al sector textil (obrajes) y la administración de los azogues se trasladó a la capital virreinal. Puebla dejó de ser un importante foco redistribuidor de mercancías europeas al perder en 1722 el control de los productos que llegaban en las flotas. Casi todos los sectores de la economía poblana se vieron afectados y el empobrecimiento de la ciudad fue una realidad palpable. Las condiciones de vida se deterioraron, afectando especialmente a los sectores populares.

Así también, es de destacar que la salubridad urbana era deplorable; los hábitos de higiene personal, el aseo de las viviendas, el hacinamiento, la contaminación del agua y alimentos, la existencia de desechos orgánicos en descomposición en la vía pública, la proliferación de muladares, la convivencia con animales de todo tipo (canes, felinos, ratas, puercos, equinos, vacunos, caprinos y sus parásitos), la defecación al aire libre, el tratamiento de diversas actividades artesanales y la existencia de cementerios mal ventilados en el interior de las Iglesias, crearon condiciones favorables para la difusión del bacilo.

\section{El matlazahuatl en Puebla}

Comenzó el año 1737 con la preocupación de la mortífera enfermedad que afectaba al valle de México. En ocasiones anteriores, las "pestilencias" habían golpeado con dureza a Puebla y, para completar el panorama, 1736 había sido un año malo; la sequía ocasionó problemas en el abastecimiento de granos y generó malestar y hambre al elevarse hacia finales del mismo los precios del maíz. De ahí que existiera inquietud,

20 La ciudad de Puebla se convirtió en un centro religioso de primer nivel en la Nueva España, gracias a su ubicación privilegiada, en la ruta del puerto de Veracruz a la capital y, por ser el único centro urbano erigido para el establecimiento de población española. 
Puebla de Los Angeles en el Siglo XVIII

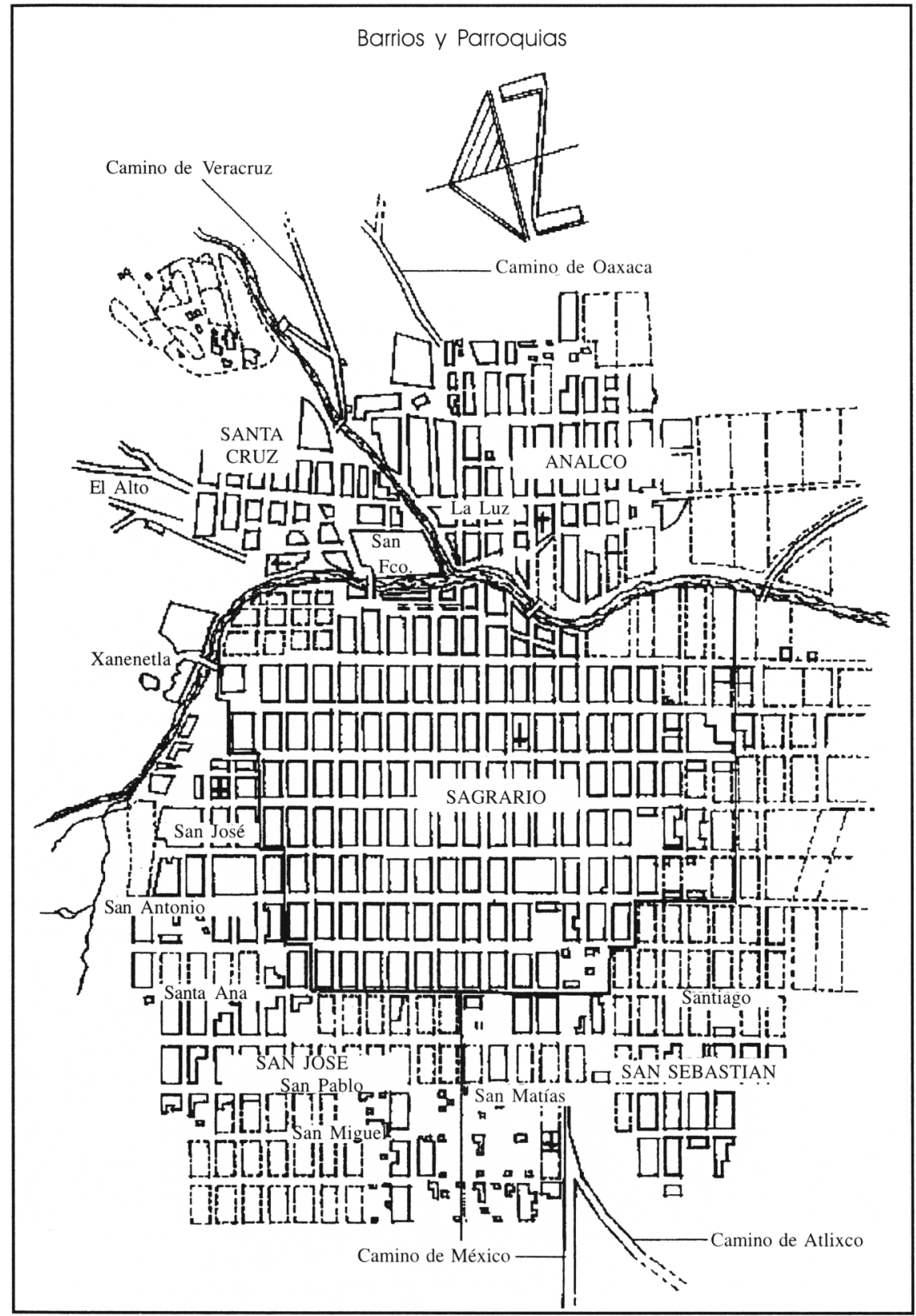


especialmente en los barrios indígenas, no obstante nada podían hacer, todo dependía de la resistencia biológica de la población y de las medidas que adoptaran las autoridades municipales, pero el Ayuntamiento poblano no determinó ninguna providencia especial destinada a resguardar el centro urbano de la peste que se extendía por todo el territorio novohispano. Tal vez, al igual que en Valladolid (actual Morelia), los regidores consideraron que se trataba solamente de una enfermedad de indios, por lo que no le concedieron demasiada importancia. ${ }^{21}$

Además, la ciudad no atravesaba por sus mejores momentos. Los problemas que normalmente debía solucionar el Cabildo se habían agudizado desde años anteriores debido a la crítica situación financiera de la corporación. Puebla tenía serios problemas de abastecimiento de agua; canales, acueductos y fuentes necesitaban de una fuerte inversión de capital —alrededor de \$4.000 — según expresaba Joseph de Medina, maestro mayor del arte de arquitectura, ${ }^{22}$ por lo que la distribución del vital líquido dependía fundamentalmente de la pericia del cañero. La permanente y crónica mala situación financiera de la institución había llevado desde comienzos de 1736 a limitar al máximo los gastos, de tal manera que el obrero mayor no podía "gastar mas cantidad que la de sinquenta pesos" en qualquier obra pública. ${ }^{23}$

El matlazahuatl no se hizo esperar; desde comienzos de febrero la población indígena asentada en los barrios del nor-poniente comenzó a verse afectada. La peste arribó a Puebla de los Ángeles por el camino de México y siguió la huella de la rata y de los hombres. En una paca de lana ingresó al centro urbano la rata enferma y se estableció una estrecha relación entre lana-rata-pulga-hombre-piojo. Los barrios indígenas de San Antonio, Santa Ana y San Pablo de los Naturales, en donde se concentraban y vivían en deplorables condiciones un gran número de hilanderos, se convirtieron en el foco originario desde donde se difundió a todo el centro urbano. Desde esos momentos la ciudad se vio inmersa en un clima de terror, pues nadie se

21 Claude Morin comenta sobre el caso de la ciudad de Valladolid (hoy Morelia): "los regidores no discutían el asunto en sus reuniones periódicas, pues los notables no se preocupaban de la epidemia porque se consideraba un mal de los indios". Morin, Claude: Michoacán en la Nueva España del siglo XVIII. Crecimiento y desigualdad de una economía colonial, México, 1979, pág. 54.

22 Archivo Ayuntamiento de Puebla, Libro de Cabildos (en adelante, AAP, LC), n. ${ }^{\circ}$ 43, fol. 380 vto.

23 Ibídem. fol. 251 vto. El 2 de enero de 1736 el Cabildo designó como obrero mayor al regidor don Juan Joseph de Gainza, al que señaló que debido a "los ahogos financieros" de la corporación municipal, "no ha de poder gastar mas cantidad que la de sinquenta pesos en qualquier obra que se ofresiere, porque pasando de ellos ha de dar quenta a esta Novillísima ciudad para que probea del remedio combeniente..." 
encontró a salvo. El matlazahuatl se ensañó especialmente con los pobres y desamparados indígenas, aunque cubrió también su cuota de españoles. ${ }^{24}$

La terrible enfermedad ganó fuerza en el mes de marzo hasta alcanzar su punto más álgido en junio y julio. Durante nueve meses los barrios de la ciudad vivieron bajo una zozobra permanente. En Analco, la Luz y los Remedios, al oriente de la traza española, así como también en San Sebastián, Santiago y San Miguel, barrios ubicados al poniente, amanecían cadáveres tirados en las calles o en los atrios de las iglesias, muchos de los cuales — según señala el párroco de Analco don Miguel Ortiz- eran "de los que tiraban de otra feligresía" o, de otras "jurisdicciones por no aber sido conosidos de los vecinos de dicho nuestro Curato". ${ }^{25}$ Mientras en la parroquia de San Sebastián fueron enterrados 234 desconocidos, en Analco la cantidad se elevó a 1,776, el $53.33 \%$ de los entierros de la parroquia correspondientes a ese año.

Por su parte, el centro de la ciudad, el área más populosa, que concentraba las principales actividades económicas, políticas, culturales y religiosas, no salió indemne. Si bien el impacto proporcionalmente fue menor que en los barrios, sufrieron por igual ricos y pobres, españoles y mestizos, indios y castas.

\begin{tabular}{lcr}
$\begin{array}{l}\text { CIUDAD DE PUEBLA. MATLAZAHUATL } \\
\text { Parroquias }\end{array}$ & Entierros & \multicolumn{1}{c}{$\%$} \\
\hline Sagrario & 1.773 & 23.07 \\
San José & 1.232 & 16.03 \\
Analco & 3.330 & 43.33 \\
Santa Cruz & 642 & 8.35 \\
San Sebastián & 708 & 9.21 \\
\hline Totales & 7.685 & 100.00
\end{tabular}

Fuente: Archivos parroquiales, Ciudad de Puebla

24 El angel de la muerte se llevó a los regidores capitán don Joseph Antonio Diez de Córdova y don Lucas Sáenz de Enziso, al licenciado don Diego de Negra, notario público de la ciudad, al capitán don Bartolomé de Santander y a los médicos bachiller don Pedro de Aguayo, bachiller don Antonio de Heredia y al bachiller don Miguel Robledo; el 19 de julio al obispo de la diócesis de Puebla, doctor don Benito Crespo, entre otros notables de la ciudad. También murieron a consecuencia del matlazahuatl más de 20 sacerdotes. Archivo Parroquial del Sagrario Metropolitano, libro de defunciones de españoles y mestizos, 1736-1743.

25 Archivo Parroquial del Santo Angel Custodio (Analco), libro de defunciones de españoles, mestizos, negros y mulatos, 1736-1755. 
Frente a la crisis, el Cabildo se encontró desorientado al no haber elaborado una política preventiva o un plan de emergencia. En la medida de sus escasas posibilidades otorgó algunos subsidios destinados a sufragar gastos de medicinas, alimentos y ropa para los pobres enfermos de la cárcel pública y de los hospitales, pero el inexorable avance de la peste superó con rapidez asombrosa la disponibilidad del dinero existente en las arcas de la ciudad. Las súplicas y peticiones de auxilio sonaban diariamente en el edificio municipal. Fray Bernardino Monsón, prior del hospital de San Juan de Dios, solicitó ayuda financiera para sufragar los elevados gastos que implicaba tener que curar y alimentar a más de doscientos enfermos que albergaban en el nosocomio, fundamentándose en lo exiguo de sus ingresos que provenían - en tiempos normales - de las limosnas, pero ante la apremiante situación ocasionada por la epidemia no alcanzaban, "aun los que han franqueado la caridad ardientísima de nuestro Ilustrisimo Prelado y de otras personas particulares". ${ }^{26}$ En el mismo tenor llegaron al Ayuntamiento solicitudes de auxilio del convento-hospital de convalecientes de Nuestra Señora de Bethlem ${ }^{27}$ y del hospital del Señor San Roque. Este último, aunque pequeño y con capacidad para 50 enfermos, habilitó otra sala que llenó rápidamente. ${ }^{28}$ Situación similar acontecía en el Real Hospital de San Pedro y en diversas enfermerías "que ha[bía] erigido la caridad pública para curación de los pobres enfermos". ${ }^{29}$

Ante la gravedad de la situación el Cabildo acudió el 9 de mayo ante el virrey-arzobispo don Juan Antonio de Vizarrón y Eguiarreta, para solicitarle ante "lo extenuado en que se encontraban sus propios", ${ }^{30}$ se le autorizara tomar del ramo de tres cuartillas la cantidad de 6.000 pesos. La respuesta del virrey-arzobispo fue rápida y positiva: mandó

"se entreguen por aora de los efectos de tres quartillas de la ciudad de la Puebla, los seis mill pesos que pide el cavildo y aiuntamiento de ella, para que de las providencias a hospitales, medicinas y alimentos conducentes al alivio de los pobres enfermos de dicha ciudad...." ${ }^{31}$

26 Ibídem, fols. 319r-320r.

27 "Fray Domingo del Salvador, actual Presidente del Convento de Religiosos de Nuestra Señora de Bethlem de esta ciudad (...) digo: que con la ocasión del contagio y peste con que Dios Nuestro Señor ha sido servirnos castigarnos, no aviendo otra casa de conbalesensia a que puedan acogerse los dolientes que salen en cresido número de los hospitales que ha erigido la caridad pública para su curasión han ocurrido a la nuestra...". Ibídem, fol. 318r.

28 Ibídem, fols. 318v-319r y 329vto.

29 Ibídem, fol. 318r.

30 Ibídem, fol. 324r.

31 Ibídem, fol. 324r. 
Inmediatamente, la corporación municipal designó a "los capitanes y rexidores don Joseph de Mendoza y Escalante, theniente de alguacil maior y don Juan Joseph de Gaenza, alcalde ordinario"32 como comisarios responsables del otorgamiento y distribución de los fondos autorizados por el virrey. Estos funcionarios, después de realizar un análisis detenido de la situación existente en los distintos nosocomios, reconociendo que el obispo de Puebla contribuía semanalmente para su sostenimiento, y además que tenían "entendido, que el cristianísimo celo de dicho Ilustrisimo Señor casso que faltase alguna cosa para este intento, estenderá la limosna de forma que no se heche de menos qualquiera contribución de esta novilisima ciudad", ${ }^{33}$ consideraron conveniente canalizar el grueso de los fondos en

"socorrer o fomentar el hospital de Señor San Roque, para que reciviendose alli todos los enfermos que pudieren comodamente estar, se hagan por esta novilisima ciudad las contribuciones semanarias, fuera de lo que otras limosnas han estado hasta la presente ocasion manteniendo el dicho hospital". ${ }^{34}$

No obstante las consideraciones expuestas por los capitulares Mendoza y Escalante y Gaenza, se hizo extensiva la contribución a los nosocomios de San Juan de Dios y de Bethlem, aunque hacia el de San Roque se canalizaron los mayores esfuerzos. El mayor hospital de Puebla, el Real de San Pedro, dependió exclusivamente de las contribuciones realizadas por el Cabildo eclesiástico, ${ }^{35}$ aunque en esos momentos se encontraba bajo la administración de los Juaninos.

Frente al "contagio y peste con que Dios Nuestro Señor a sido servido castigarnos", ${ }^{36}$ el fervor popular llenó iglesias, templos y capillas de la ciudad, especialmente en las que se encontraban milagrosas imágenes. Así, San Roque y San Sebastián, protectores contra la peste, se convirtieron en el centro de atención de un pueblo indefenso ante la mortal enfermedad. Novenarios, procesiones y rogativas fueron permanentes con la intención de "pacificar la justicia divina" ${ }^{37}$ Jesús Nazareno, cuya imagen se veneraba en la Iglesia parroquial de San José, fue objeto, por parte de pobres y ricos, de plegarias multitudinarias al ser trasladado solemnemente en pro-

32 Ibídem, expedientes sobre vacunas y salubridad, tomo 198, fol. 22 vto.

33 Ibídem, LC, n. ${ }^{\text {4 } 43, ~ f o l . ~ 329 v t o . ~}$

34 Ibídem.

35 Ibídem, expedientes sobre vacunas y salubridad - Tomo 198, fol. 23r. Véase también Izquierdo, José Joaquín: Raudón. Cirujano poblano de 1810, México, 1949, pág. 56.

36 AAP, LC, n. ${ }^{\circ} 43$, fol. 321 vto.

37 Ibídem, fols. 321vto y 336vto-337r. 
cesión a la Iglesia Catedral, en donde se le instaló en un altar especial. El Ayuntamiento participó activamente en la organización de estos eventos, erogando en el novenario realizado al "glorioso Sr. San Sebastián para que aplacara la peste", 89 ps., 7 rs. en ceras y 82 ps., 1 r. en chocolate y vino "que se dió a las sagradas religiones que asistieron los nuebe días". ${ }^{38}$ A pesar de las fervientes y devotas súplicas, el matlazahuatl reinó allí a lo largo del año.

A finales de junio, cuando la mortandad causaba estragos, llegaron a Puebla los regidores de la ciudad de México don Felipe Cayetano de Medina y Zaravia y don Joseph Francisco de Aguirre y Espinosa, acompañados por el arcediano de la Iglesia Catedral capitalina don Alfonso Francisco Moreno y, por el canónigo magistral don Bartolomé Phelipe de Ita y Parra, quienes portaban una carta que el Ayuntamiento de la ciudad de México enviaba al de Puebla, en donde se expresaba que

"Los fabores que la Nueba España merece a nuestra Señora por su deligneasion milagrosa que se venera en el Santuario de Guadalupe los deseos del común y la publica devoción con que la aclaman patrios y foraneos y la mortal epidemia que de la Metrópoli a las demás poblaciones lastimosamente se difunde: nos estimulan para elegir de Particularisima Patrona a la emperatriz divina en su admirable imágen expresada....". ${ }^{39}$

¿Puebla se había olvidado de la virgen del Tepeyac?, ¿era necesario un nuevo escudo protector?, ¿las vírgenes de los Remedios, del Rosario, del Pilar y del Carmen, no habían intercedido para aplacar la justicia divina sobre la ciudad más hispana y católica de la Nueva España?. La solicitud del Ayuntamiento de México motivó una larga discusión; se llegó a considerar que no era necesario prestar juramento debido a que "ha ochenta años que está jurada por Patrona de esta ciudad la Soberana reyna de los Angeles Maria Sanctissima nuestra Señora con el titulo de Guadalupe". ${ }^{40}$ No obstante, acuerda asistir solemnemente al acto de juramento, debido a "la presente miserable vida y calamidades de ellas en las pestes y otros castigos de que la misericordia divina usa para escarmiento de los hombres". ${ }^{41}$

A medida que la epidemia causaba estragos entre la población, los problemas aumentaron. El matlazahuatl, junto con la sequía, generó serios

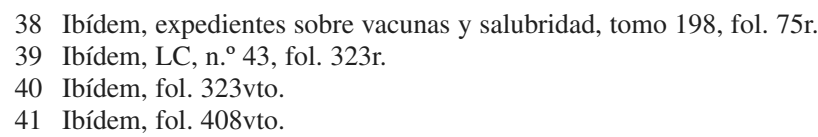


inconvenientes en el abastecimiento de agua y de diversos productos de consumo diario. A comienzos de mayo, el experimentado cañero de la ciudad Juan Pérez murió víctima de la peste. Con la finalidad de mantener el abastecimiento de agua - a pesar de la crítica condición en que se encontraban las cañerías-, se designó rápidamente en el cargo a Miguel Saqueo ${ }^{42}$ pero un mes después, debido "al poco conosimiento que el nuevo cañero tiene de los aqueductos", Puebla se había quedado, en los momentos más álgidos de la crisis, sin agua. Las quejas no se hicieron esperar: hospitales, conventos, curas párrocos, notables y pobres denunciaron la crítica situación que ocasionaba la falta del vital líquido. El incompetente funcionario tuvo que ser reemplazado por un empírico, Juan Antonio Pérez, "hijo del cañero difunto por tener conocimiento de los aqueductos y cañerías" existentes en el centro urbano. ${ }^{43}$

Paralelamente, la peste ocasionó otro dolor de cabeza a los sufridos habitantes de la Puebla y a sus autoridades. A

"causa de la epidemia y mortandad padecida en ella y sus contornos se escasearon con exeso algunos frutos de la tierra y especialmente el carbón". ${ }^{44}$

El Cabildo tomó inmediatamente algunas medidas destinadas a garantizar el abasto de aquellos productos que escaseaban, especialmente el necesario combustible, pero tal vez la prisa por encontrar soluciones, la tensión generada por la crisis o, simplemente la falta de trabajadores, llevó a los regidores a cometer el mismo error que el generado con el problema del agua al designar como encargado de organizar y aplicar las medidas conducentes a solucionar el caso, al capitán y regidor don Pedro Pérez de Tagle, funcionario que ocasionó mayores inconvenientes que soluciones. Su actividad motivó el temor de carboneros y leñeros, así como también, de veleros y jaboneros,

"por ser tan corto el espíritu de los indios que les pareció se pretendía cobrar alcavala, se han retirado y carece la ciudad de un género tan preciso para la vida humana [como el carbón y la leña], siendo esto digno de reparo, como también el que con las violencias de dicho capitán por querer hacer justicia por si solo quitando pan, belas y jabón, y otras cosas sin concurso de sus mercedes, repartiendo multas de que todo el vecindario esta temeroso". ${ }^{45}$

42 Ibídem, fol. 320 vto.

43 Ibídem, fol. 337r.

44 Ibídem, fol. 363r.

45 Ibídem, fol. 363r. 
Ante el temor de que la actuación del funcionario provocara un tumulto, el Cabildo comisionó al capitán Pérez de Tagle para realizar otras actividades, al mismo tiempo que acordó tomar "algunas providencias a fin de que buelba la leña, maderas y carbón a su antigua corriente...”. El matlazahuatl había desquiciado la vida de la ciudad.

\section{Unos breves comentarios demográficos}

El año de 1737 fue recordado en Puebla durante mucho tiempo. Como en todo centro urbano colonial, sus habitantes estaban acostumbrados a convivir diariamente con la muerte y desde su fundación diversas pandemias y epidemias habían afectado a su población, tan es así que sólo cuatro años antes (1733-1734) la rubeola hizo aumentar notoriamente el número de entierros. A pesar de ello, los poblanos no recordaban una enfermedad tan letal como el matlazahuatl ${ }^{46}$ que ocasionara un número tan elevado de víctimas. En ocho meses envió a la tumba 7.167 personas adultas, ${ }^{47}$ cifra que representó el $93.26 \%$ de las defunciones de ese año (7.685), tal como puede verse en el cuadro de la página siguiente.

Desde finales de enero la peste comenzó a cobrar sus primeras víctimas y, a partir de la segunda semana del mes de febrero los decesos aumentaron de forma notoria; las defunciones se incrementaron vertiginosamente durante abril hasta alcanzar la cima en mayo (1.470). La crisis ocasionada por el matlazahuatl no había pasado todavía. Durante todo el mes de junio el número de muertos llegó a 1449. Fue a mediados de julio cuando empezó a perder fuerza: lentamente primero y durante agosto más aceleradamente, los sepelios disminuyeron. A finales de octubre el peligro había quedado atrás aunque hasta febrero de 1738 se produjeron algunos casos. En un solo año, la Iglesia registró el fallecimiento de 7.685 personas adultas; a esta cifra habría que agregar los niños que murieron a causa de la peste y todos aquellos casos que por diversos motivos no fueron anotados en los libros parroquiales. Si tomamos como punto de referencia el padrón de 1746 (50.366 habitantes), el matlazahuatl — tomando sólo en consideración a la población adulta registrada en los libros de defunciones- envió al sepulcro al $15.26 \%$ de la población de la ciudad.

46 La última epidemia de matlazahuatl que afectó a la ciudad fue en 1694-1696;habían pasado 42 años desde la anterior epidemia. Cuenya, Miguel Angel: Epidemias y mortalidad..., págs. 22-23.

47 Debido al gran subregistro de niños existentes, nuestro análisis se concentra exclusivamente sobre la población adulta. 
ENTIERROS MATLAZAHUATL 1737 (adultos)

Ciudad de Puebla. Distribución por parroquias

\begin{tabular}{lrrrrrrr} 
Meses & Sagrario & S. José & Analco & S. Cruz & S. Sebas. & Total & $\%$ \\
\hline Enero & 74 & 45 & 19 & 9 & 12 & 159 & 2.06 \\
Febr. & 64 & 99 & 57 & 42 & 16 & 278 & 3.61 \\
Marzo & 138 & 245 & 209 & 8 & 87 & 766 & 9.96 \\
Abril & 274 & 190 & 647 & 120 & 178 & 1.409 & 18.33 \\
Mayo & 282 & 100 & 806 & 104 & 178 & 1.470 & 19.12 \\
Junio & 278 & 217 & 752 & 79 & 123 & 1.449 & 18.85 \\
Julio & 248 & 188 & 474 & 78 & 47 & 1.035 & 13.46 \\
Agosto & 147 & 64 & 244 & 92 & 19 & 566 & 7.36 \\
Sept. & 100 & 23 & 41 & 19 & 11 & 194 & 2.52 \\
Oct. & 72 & 24 & 35 & 3 & 11 & 145 & 1.88 \\
Nov. & 49 & 25 & 25 & 4 & 15 & 118 & 1.53 \\
Dic. & 47 & 12 & 21 & 5 & 11 & 96 & 1.25 \\
\hline Totales & 1.773 & 1.232 & 3.330 & 642 & 708 & 7.685 & 100.00 \\
\hline \multicolumn{1}{c}{$\%$} & 23.07 & 16.03 & 43.33 & 8.35 & 9.21 & 100.00 &
\end{tabular}

Fuente: Archivos parroquiales de Puebla, libros de defunciones

La pandemia afectó de manera especial a los indígenas. Si bien como grupo étnico no era mayoritario, predominando españoles y mestizos, el $50.28 \%$ del total de los entierros correspondieron a indígenas, porcentaje que se elevaría al $73.14 \%$ si contabilizamos los 1.809 casos en los que no se anotó pertenencia étnica por ser difuntos desconocidos que se encontraron tirados en la calle o atrios de las Iglesias, pero que en su gran mayoría pueden haber pertenecido a este sector. Españoles, mestizos y castas, también sufrieron con el matlazahuatl y sumaron en conjunto 2.012 defunciones, lo que representó el $26.18 \%$ del total. Este comportamiento étnico diferencial frente a la pandemia, es mucho más visible a nivel parroquial.

Ahora bien, un índice que muestra desde otra perspectiva la gravedad de la crisis, es la mortalidad por sexo. El índice de masculinidad ${ }^{48}$ nos per-

48 El índice de masculinidad mide la relación entre defunciones masculinas y femeninas. Se obtiene dividiendo el número de defunciones masculinas entre femeninas y multiplicando el resultado por cien. 
mite observar el comportamiento diferencial masculino/femenino (M/F). $\mathrm{Si}$ a las 7.685 defunciones de adultos registrados, le restamos todos aquellos casos en los que no se discrimina el sexo y sacamos el índice de masculinidad, nos encontramos con un valor muy bajo (78.75), es decir, el matlazahuatl provocó en Puebla de los Angeles una sobre mortalidad femenina (55.94\%). Sobre el particular, es importante destacar, que al tratarse de población adulta, un alto porcentaje de los decesos femeninos debe haber correspondido a mujeres en edad reproductiva $y$, muchas de ellas embarazadas.

$$
\begin{aligned}
& \text { MATLAZAHUATL DE } 1737 \text { EN LA CIUDAD DE PUEBLA } \\
& \text { (entierros por grupo étnico) }
\end{aligned}
$$

\begin{tabular}{|c|c|c|c|c|c|c|}
\hline Parroquias & indígenas & esp. & mest. & castas & $S / E$ & totales \\
\hline Sagrario & 487 & 533 & 352 & 401 & & 1.773 \\
\hline San José & 781 & 173 & & 8 & & 1.232 \\
\hline Analco & 1.468 & 31 & 45 & 19 & 1.767 & 3.330 \\
\hline San Sebast. & 558 & \multicolumn{2}{|c|}{108} & & 42 & 708 \\
\hline Santa cruz & 570 & 26 & 35 & 11 & & 642 \\
\hline Totales & 3.864 & 2.012 & sp./mes & castas) & 1.809 & 7.685 \\
\hline$\%$ & 50.28 & 26. & $\mathrm{sp} . / \mathrm{m}$ & castas) & 23.53 & $100 .($ \\
\hline
\end{tabular}

Fuente: Archivos parroquiales, ciudad de Puebla

Esta mortalidad diferencial por sexo también se observa a nivel étnico, siendo el indígena en donde existiría un mayor equilibrio; en este grupo el índice de masculinidad fue de 95.34, mientras que entre los entierros pertenecientes al sector no indígena de la población, la relación masculino/femenino presenta una marcada desproporción. El índice de masculinidad correspondiente a españoles es de 62.45 , mientras que entre los mestizos desciende a 47.35 y entre las castas a 48.32 . En las parroquias, se puede observar con mucha mayor claridad el comportamiento diferencial de la mortalidad por sexo.

La gravedad del matlazahuatl queda demostrada al comparar los niveles de mortalidad de 1737 respecto a la registrada en los años "normales" anteriores, en donde no sólo se estableció diferencias étnicas sino que tam- 
bién indígenas, españoles, mestizos y castas no presentaron un comportamiento similar en las distintas parroquias de la ciudad. La población indígena resintió la peste con mayor o menor intensidad dependiendo de diversos factores: condiciones de vida, hacinamiento, adscripción laboral, insalubridad reinante, etc.; de esta manera se observa que en algunas parroquias el incremento en el número de entierros fue mayor que en otras respecto a la media registrada en años "normales" anteriores: en San Sebastián éstos se elevaron 23.7 veces, en Analco 11, en Santa Cruz 7 y en San José 4.5. Entre españoles y mestizos también se observa una situación similar. Durante 1737 los registros de defunciones de españoles existentes en el Sagrario Metropolitano se incrementaron 3.5 veces por encima de la media, mientras que en San José el aumento fue de 2.7 veces. Por su parte los mestizos que vivían en San José vieron incrementar el número de tumbas del sector 8 veces por encima de la media registrada en años anteriores, 4 en San Sebastián y 3.6 en el Sagrario Metropolitano.

\section{MATLAZAHUATL 1737. CIUDAD DE PUEBLA (entierros por sexo)}

\begin{tabular}{|c|c|c|c|c|c|c|c|c|c|c|c|c|}
\hline \multirow[t]{2}{*}{ Parroquias } & \multicolumn{2}{|c|}{ indígenas } & \multicolumn{2}{|c|}{ españoles } & \multicolumn{2}{|c|}{ mestizos } & \multicolumn{2}{|c|}{ castas } & \multicolumn{2}{|c|}{ s/etnia } & \multicolumn{2}{|c|}{ totales } \\
\hline & $H$ & $M$ & $H$ & $M$ & $H$ & $M$ & $H$ & $M$ & $H$ & $M$ & $H$ & $M$ \\
\hline orario & 182 & 224 & 190 & 308 & 96 & 24 & 121 & 26 & & & 589 & 1.043 \\
\hline San & 384 & 39 & 61 & 112 & 88 & 162 & 10 & 8 & & & 543 & 689 \\
\hline 5. Se & 250 & 311 & $45^{\prime}$ & $59 *$ & & & & & 20 & 23 & 315 & 393 \\
\hline Analc & 766 & 690 & 11 & 20 & 26 & 34 & 7 & 12 & & & 810 & 756 \\
\hline Sta. Cruz & 260 & 310 & 14 & 15 & 13 & 27 & 6 & 5 & & & 293 & 357 \\
\hline otales & 1.842 & 1.932 & 321 & 514 & 223 & 471 & 144 & 298 & 20 & 23 & 2.550 & 3.238 \\
\hline & & 51 & & 61.1 & & & & & & .0 & 44.1 & 55.9 \\
\hline I. Masc. & 95 & & 62 & & 47 & 35 & 48 & & 86 & & & 8.75 \\
\hline
\end{tabular}

Nota: * españoles y mestizos

A diferencia de la viruela, el sarampión y otras enfermedades, la peste superó barreras étnicas y socioeconómicas, empero, la miseria, las condiciones de vida, la convivencia con animales, los hábitos higiénicos, el hacinamiento, etc., generaron condiciones diferentes entre el centro y los barrios. Indígenas y castas fueron los grupos que sintieron con mayor 
intensidad los efectos de la terrible enfermedad; el golpe fue tan severo que las consecuencias se sintieron durante muchos años, mientras que mestizos y españoles se recuperaron rápidamente. Las condiciones sociales establecían nuevamente la diferencia, los pobres y miserables recibían el "castigo divino", y el clamor de los indígenas en los templos se escuchaba en toda la ciudad. Muchos deben haber elevado la misma plegaria que una india vieja realizó a la virgen de Guadalupe en la ciudad de México: "O! no muramos todos Madre nuestra. Y si han de morir, Señora, los indios, que mueran también los españoles". ${ }^{49}$

49 Cabrera y Quintero, Cayetano: Escudo de armas..., pág. 71. 